\title{
The fracture behaviour of single wood fibres is governed by geometrical constraints: in situ ESEM studies on three fibre types
}

\author{
Michaela Eder · Stefanie Stanzl-Tschegg • \\ Ingo Burgert
}

Received: 19 September 2007 / Published online: 2 September 2008

(C) The Author(s) 2008. This article is published with open access at Springerlink.com

\begin{abstract}
In situ tensile tests were performed in an environmental scanning electron microscope (ESEM) on earlywood, transition wood and latewood cells of Norway spruce (Picea abies [L.] Karst.). In order to examine the single wood fibres in a wet state, a specially designed tensile testing stage with a cooling device was built. The fracture behaviour of the cell types was studied at high resolution while straining. Different failure mechanisms were observed for the three tissue types. The thin-walled earlywood fibres showed tension buckling which gave rise to crack initiation and resulted in low tensile strength, whereas thick-walled latewood fibres predominately failed by transverse crack propagation without fibre folding.
\end{abstract}

\section{Introduction}

Environmental scanning electron microscopy (ESEM) is a powerful tool in biomaterials research due to its applicability in observing the biological sample in a wet state at high magnifications. ESEM was established in the late 1980s and differs from conventional scanning electron microscopy (SEM) in two aspects, namely: (1) a high pressure of up to $\sim 30$ torr is permitted in the sample chamber and (2) insulating specimens can be imaged without a conductive coating (Stokes 2003). By utilising

\footnotetext{
M. Eder $(\bowtie) \cdot$ I. Burgert

Department of Biomaterials, Max-Planck-Institute of Colloids and Interfaces,

Research Campus Golm, Am Mühlenberg 1,

14476 Potsdam-Golm, Germany

e-mail: michaela.eder@mpikg.mpg.de

M. Eder $\cdot$ S. Stanzl-Tschegg

Department of Material Sciences and Process Engineering,

Institute of Physics and Materials Science, BOKU,

University of Natural Resources and Applied Life Sciences,

Vienna, Austria
} 
water vapour as an imaging gas, with its special thermodynamic properties and low ionization potential (Fletcher et al. 1997), samples can be kept in a wet state provided that they are sufficiently cooled. The number of ESEM investigations published has been less than expected, due to a lower resolution and brilliance of the images compared to high vacuum condition in a conventional SEM combined with a cryostage, which is a much better alternative when structural examination is intended exclusively. However, in terms of mechanical studies combined with electron microscopy the main advantage of an ESEM mode is that the mechanical properties can be investigated on moisturized samples, which is crucial for biological samples.

In situ tensile studies combined with electron microscopy have already been carried out on various plant tissues. Studies on wet tissues [onion (Allium cepa) and algae (Chara corallina)] were performed by Donald et al. (2003), but the majority of studies on wood were operated in the dry state. In various microfracture studies on dry thin wood specimens, specific crack propagation mechanisms for different tissue types were examined (Frühmann et al. 2003a, b; Sippola and Frühmann 2002). Mechanical tests on single fibres were also carried out by Mott et al. (1995, 1996). They strained single pulp fibres in an ESEM chamber and analysed the recorded images by digital image correlation. It was shown that microstrain distribution was not uniform along the fibres. Bos and Donald (1999) performed a modified loop test on single flax fibres inside an ESEM chamber and studied the deformation patterns at the compressive and tensile sides of the loop.

A new microtensile testing device was designed to test single fibres in the wet state inside the chamber of an ESEM. The fibres were mechanically isolated (Burgert et al. 2003, 2005) which means that the cell wall polymers were not only retained in their natural state but also that the shape of the cells was preserved. Both, the tensile setup and the fibre properties allowed for a detailed study on the influence of fibre geometry on the fracture behaviour.

An unresolved question of single fibre mechanics is why earlywood fibres break at considerably lower stress levels than latewood fibres (stress calculation based on cell wall cross-section). Mott et al. (2002) performed tensile tests on chemically isolated earlywood and latewood single fibres and showed that the fracture strength of latewood was $73 \%$ higher than that of earlywood. In a previous work (Eder et al. 2008) it has been observed, that the fracture strength of latewood (calculated on the basis of cell wall cross-section) was almost twice as high as that of earlywood. These remarkable differences between earlywood and latewood fibres have not yet been explained entirely. By investigating fibres from an earlywood, a transition wood and a latewood region in the specially designed tensile setup in the ESEM chamber an attempt was made to reveal more details of the observed phenomenon.

\section{Materials and methods}

\section{Single wood fibres}

An adult wood block of Norway spruce was microtomed in the longitudinaltangential direction (LT). Hundred and fifty micrometre thin slices of earlywood, 
transition wood and latewood were collected which then served for the isolation of single tracheids. In order to retain the single cells in their natural state the isolation procedure was performed mechanically by using fine tweezers (Burgert et al. 2002). After isolation, the fibres for the in situ ESEM experiments were dried under glass sheets to avoid twisting (Burgert et al. 2005). The air dried fibres were then glued onto $150 \mu \mathrm{m}$ thick foliar frames using cyanoacrylate glue. Fibres were re-moistened for the in situ tensile tests. The fibres for ex situ tests were stored in glycerine to keep them in the wet state. Previously performed ex situ measurements showed no significant difference in mechanical properties between never-dried fibres and remoistened fibres. This suggests that the dried and subsequently re-moistened fibres, tested in situ in the ESEM, should have almost the same mechanical properties as never-dried fibres.

In situ microtensile testing

The mechanical behaviour of single wood cells while straining was observed in a FEI FE-ESEM, Quanta 600. In order to minimize electron skirt of the beam (e.g. Danilatos 1993), the tensile apparatus was brought as close as possible to the detector which is located directly below the final pressure limiting aperture. Tensile experiments were performed with a test speed of $0.5 \mu \mathrm{m} / \mathrm{s}$ using a microtensile testing device equipped with a $500 \mathrm{mN}$ load cell (A.L. Design) (Fig. 1).

The testing device was controlled via a graphical interface with a PC. Cables pass a feedthrough flange which allowed the microtensile tester to be controlled outside the microscope. The general principle of the device was similar to the one reported by Burgert et al. (2003). Samples had to be cooled to keep them moist under the low pressure in the ESEM chamber. For this purpose a Peltier cooling stage was located
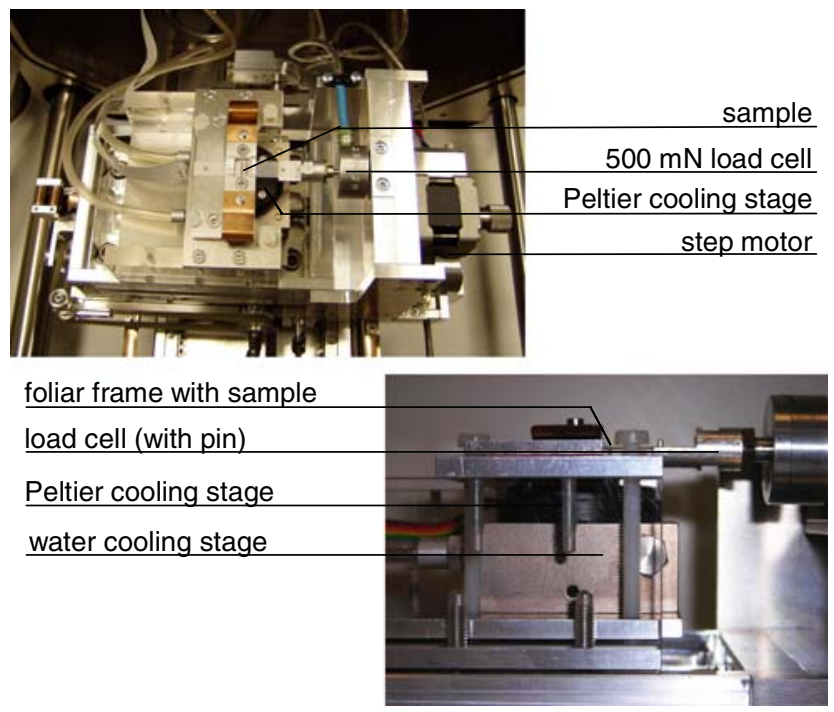

Fig. 1 Experimental setup 
below the sample and cooled the upper plate of the moveable table. Additionally, a droplet of water was placed onto the single fibre to enhance the thermal conductivity because the single fibre itself was not in direct contact with the cooled metal table. This "free-standing" of the fibre prevented damage while cutting the remaining bridges of the foliar frame before testing (Burgert et al. 2003).

After the upper plate of the moveable table, the water droplet and the sample reached a constant temperature, the pressure was reduced in the microscope chamber until the water droplet started to evaporate. When the underlying structures of the fibre became visible the evaporation was stopped immediately by increasing the pressure again. This iterative process was performed until stable conditions were achieved which both kept the sample in a hydrated state and allowed for sufficient imaging. According to Donald (1998) an electron-permeable water layer of less than $\sim 10 \mathrm{~nm}$ can be tolerated for SEM.

\section{Results and discussion}

Comparison of single fibre measurements inside and outside the chamber of the ESEM revealed a reduction of tensile strength for the fibres which were tested in situ. The data of both, in situ and ex situ measurements are shown in Table 1.

All three fibre groups (earlywood, transition wood and latewood) showed lower maximum loads when tested inside the microscope. Differences in temperature and pre-treatment of fibres (never-dried/remoistened) do not fully explain the different behaviour inside and outside. Therefore the reduction might be a result of radiation damage. It is well known that radiation damage can be a serious problem in the ESEM mode, especially when water vapour is used as an imaging gas. The radiation damage is triggered by the presence of water, because highly energetic primary electrons create radicals during the ionisation processes (Jenkins and Donald 1997; Kitching and Donald 1998). It is assumed that these radicals can lead to severe damage of the samples. For further details concerning radiation damage of water and of wet samples see e.g. Kitching and Donald (1998) or Royall et al. (2001). To minimize radiation the acceleration voltage was kept low $(8 \mathrm{kV})$ and the beam exposure time short. However, although no damage was visible in beam sensitive areas such as pits (Kifetew and Sandberg 2000), the differences in maximum loads

Table 1 Maximum loads $\left(F_{\max }\right)$ of fibres tested ex situ and in situ

\begin{tabular}{lllllll}
\hline & $\begin{array}{l}F_{\max } \\
\text { (in situ) }(\mathrm{mN})\end{array}$ & $n$ & $\begin{array}{l}\text { Tension } \\
\text { buckling }(\%)\end{array}$ & $\begin{array}{l}F_{\max } \\
(\text { ex situ) }(\mathrm{mN})\end{array}$ & $\begin{array}{l}\text { Tensile strength } \\
\text { (cell wall) }(\mathrm{MPa})\end{array}$ & $n$ \\
\hline Earlywood MFA 9.4 & $39 \pm 15$ & 11 & 91 & $120 \pm 44$ & $553 \pm 32$ & 15 \\
Transition wood MFA $7.5^{\circ}$ & $151 \pm 55$ & 11 & 32 & $242 \pm 49$ & $706 \pm 123$ & 11 \\
Latewood MFA 7.6 & $177 \pm 53$ & 12 & 8 & $367 \pm 82$ & $799 \pm 186$ & 10 \\
\hline
\end{tabular}

Tensile strength of fibres tested ex situ

$n$ number of successful measurements, buckling percentage of fibres showing cell folding, MFA microfibril angle 
inside and outside the chamber indicated that radiation damage occurred. A closer examination of the data revealed that the thin-walled earlywood fibres were more affected than the other fibre types which supports the former assumption, because the penetration depth of the electron beam should be the same for all three fibre types. This means that the proportion of radiation damage is higher for the thin- than the thick-walled samples.

Figure 2 shows the representative deformation and fracture pattern of one earlywood fibre in tension and the corresponding load-displacement curve.

In the initial part of the curve the slope was less steep because of additional deformation due to adjustments of the pin-hole assembly of the foliar frames which carried the fibre. Load drops in the force-displacement curve were caused by stops of the motor displacement required for image acquisition; the decrease in force was due to stress relaxation during pausing. Micrograph 2 a shows a section of the unloaded fibre. Apparent deformation started with a folding/collapse of the cell wall at rather low load levels and strains, indicated by the arrows in Fig. 2b. Further
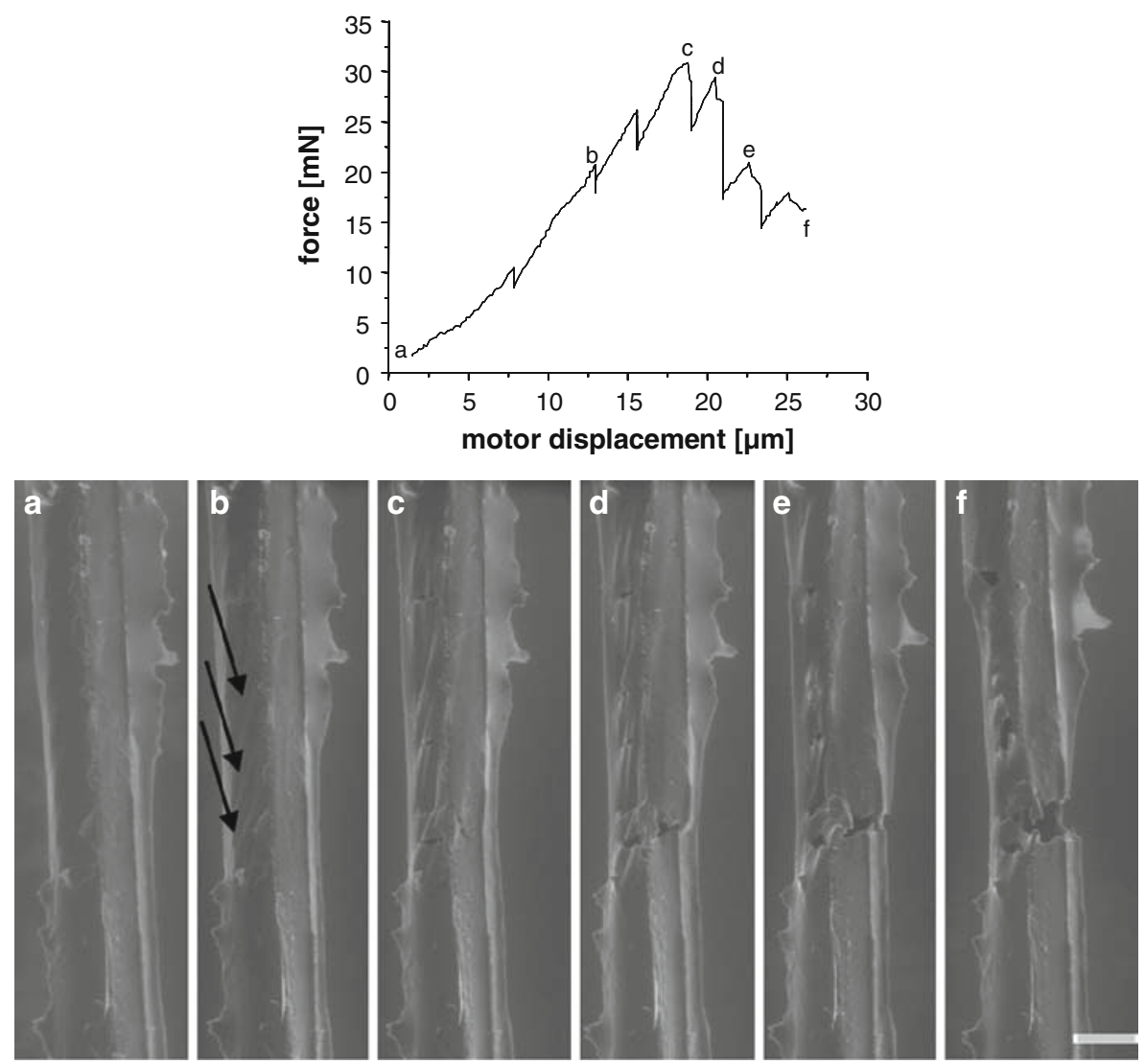

Fig. 2 Characteristic deformation pattern of an earlywood fibre and corresponding force-displacement curve; bar $50 \mu \mathrm{m} ; \boldsymbol{a}-\boldsymbol{f}$ in the diagram refer to the corresponding micrographs which are plotted below; arrows in $\mathbf{b}$ point at incipient folding/collapse of the cell wall 
straining resulted in an initiation of cracks in the neighbourhood of these folds. The simultaneous force recording showed a partial load drop when the first cracks developed. For a complete separation of the fibre additional straining was required. Surprisingly, crack formation did not necessarily proceed in the immediate vicinity of pits or pit fields.

For transition wood fibres two typical failure mechanisms were observed. In terms of the first failure pattern, fibres were separated into two parts by a crack immediately transversing the whole cell as shown in Fig. 3. At $\sim 60 \%$ of ultimate

Fig. 3 Deformation pattern of a transition wood fibre and corresponding forcedisplacement curve, bar $50 \mu \mathrm{m}$
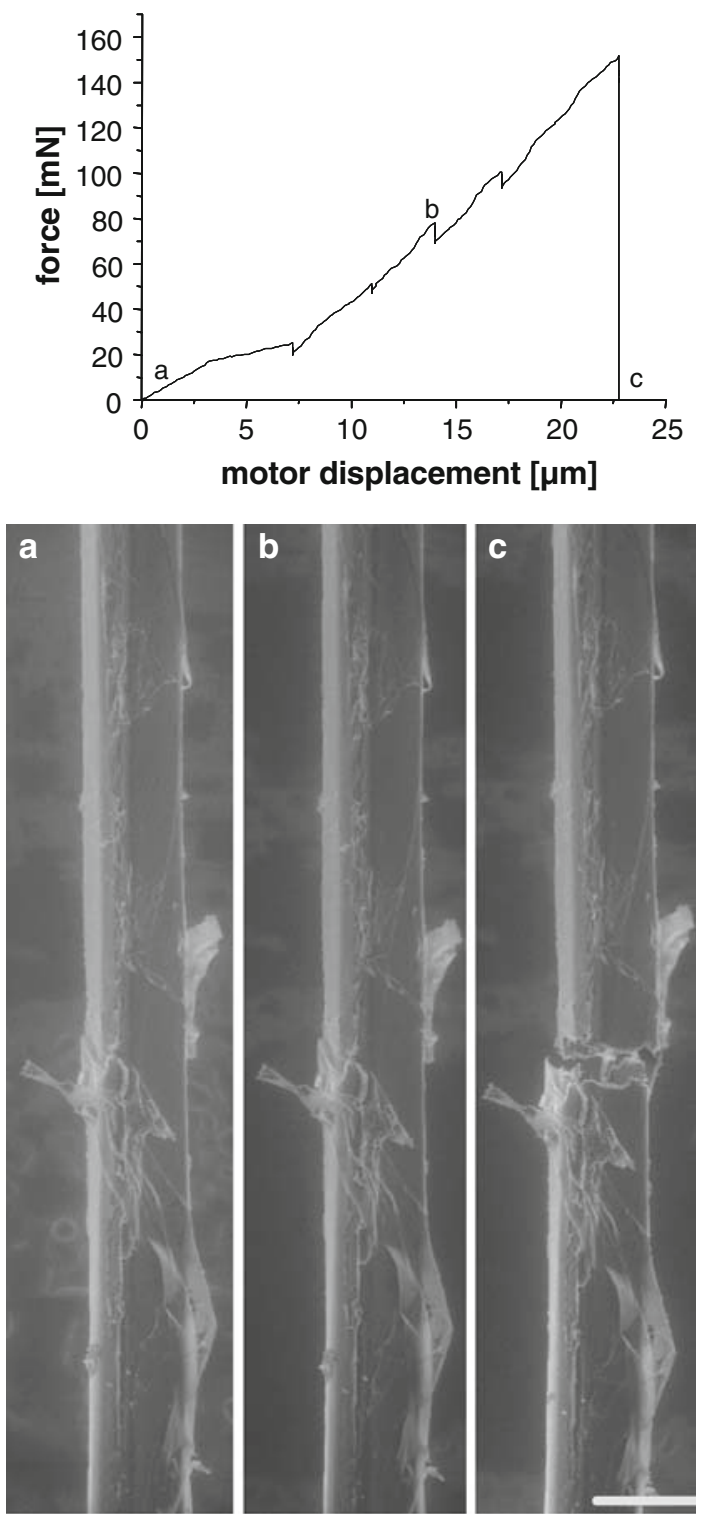
load no apparent deformation pattern was observed (3b). Even shortly before fatal fracture, crack initiation was not visible.

The second typical deformation pattern for transition wood fibres is shown in Fig. 4. The visible deformation started with a folding of the cell which preferentially occurred in the vicinity of bordered pits [upper part of the fibre in micrograph (4b)] and pit fields [lower part of the fibre in micrograph (4b)].

Similar to earlywood fibres, a partial load drop was observed when the first cracks appeared in the environment of the pit field (4c) and the fibre started to collapse. To separate the fibre completely, further straining was required (4d). Micrograph $4 \mathrm{e}$ shows the fracture path of the crack. The crack propagated through the pit field, partly parallel to the longitudinal axis of the fibre. In contrast to the earlywood fibres, cell wall folding and subsequent collapse started at considerably higher load levels and were initiated in the vicinity of structural weak points, in this case the pit field.

The common fracture pattern of latewood fibres (Fig. 5) was similar to the one shown in Fig. 3 (transition wood fibre) with a crack separating the whole cell transversally without prior visible deformation.
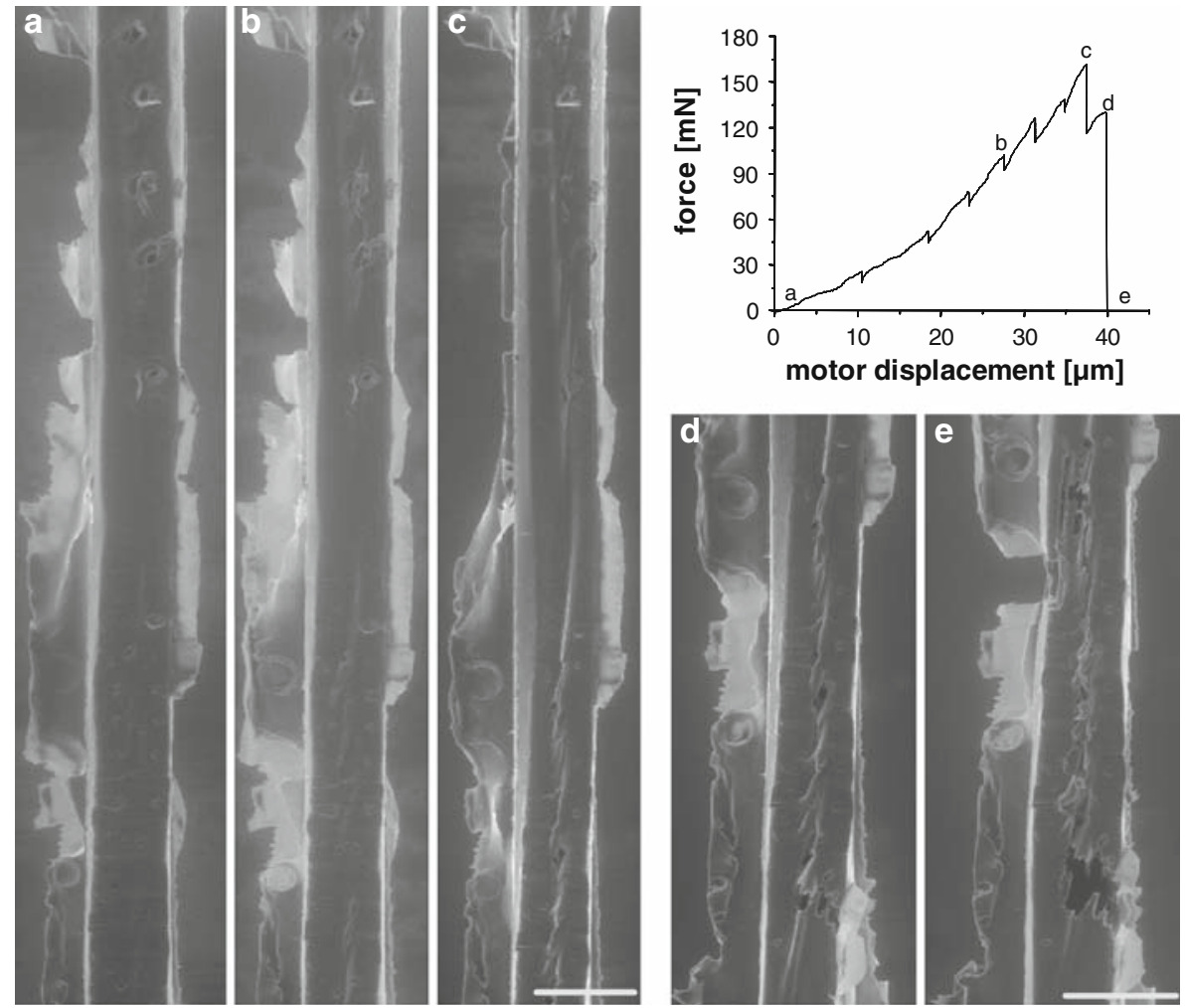

Fig. 4 Buckling of a transition wood fibre under tension and corresponding force-displacement curve, bar $50 \mu \mathrm{m}$ 

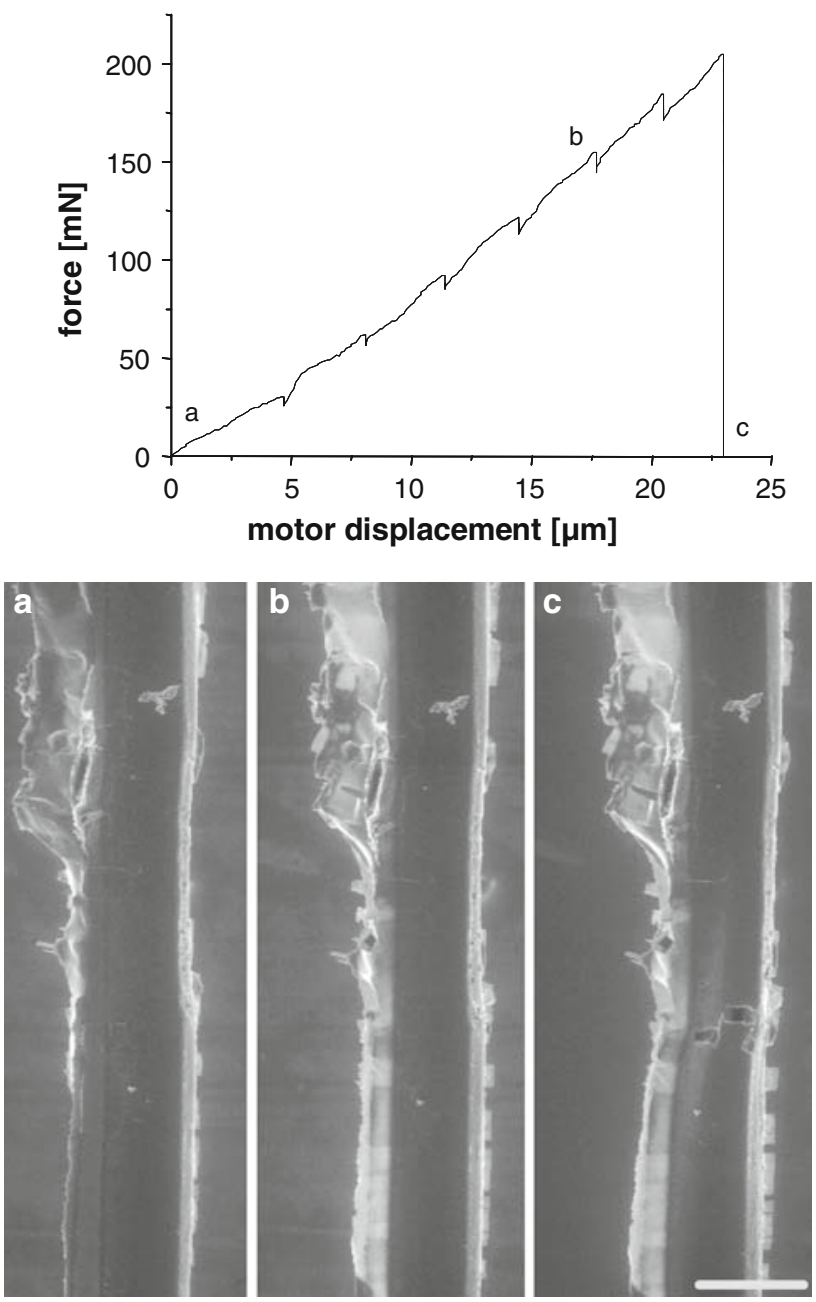

Fig. 5 Characteristic deformation pattern of a latewood fibre and corresponding force-displacement curve, bar $50 \mu \mathrm{m}$

In addition to the described fracture mechanism a folding of the cell at high load levels was observed for fibres containing a higher amount of pits or pit fields. In some cases a slight twisting of the latewood cells during straining was monitored, although torsional movement was restricted by fixing the fibre ends with glue. Presumably, structurally weak points along the fibre may promote the described twisting behaviour.

The tensile strength of the three fibre types measured in situ in the ESEM chamber cannot be directly compared because radiation damage probably influenced the ultimate forces. However, the ex situ tests clearly showed that the thin earlywood fibres were less strong than the thick-walled fibres (Table 1). Likewise Mott et al. (2002) found a lower tensile strength for earlywood fibres when 
they tested delignified fibres which fold and buckle already before tensile straining because of the loss of transverse stability caused by the lignin removal. They explained the lower tensile strength of earlywood by a higher microfibril angle and by pitting. A slightly higher cellulose microfibril angle in earlywood compared to transition wood and latewood was also found (Table 1), but due to the observed fracture patterns it was assumed for our data, that the differences between earlywood, transition wood and latewood cannot be fully explained by the slight differences in cellulose microfibril angle and pitting. The deformation studies in the ESEM showed that tension buckling took place in thin-walled fibres and that the probability of buckling decreased with decreasing cell size and increasing cell wall thickness. Comparing the failure pattern of the three fibre types, cracks in thinwalled cells were mainly initiated by cell folding and subsequent collapse, in the literature termed as "tension buckling" (Jeronimidis 1980; Pagano and Halpin 1968; Page et al. 1971). With increasing cell wall thickness and decreasing cell size visible structural weak points like bordered pits or pit fields, seemed to become more relevant in terms of crack initiation. Consequently the lower tensile strength of thin-walled earlywood fibres might be explained by tension buckling.

Pagano and Halpin (1968) studied the mechanisms of tension buckling by means of thin-walled anisotropic cylinders consisting of nylon fibers embedded in a rubber matrix at different helical angles. Tensile tests with a restriction of rotation of the samples resulted in a buckling of the cylinders. Likewise, tension buckling was observed in single fibre tests (Page et al. 1971). Page and El-Hosseiny (1983) described tension buckling in thin-walled pulp fibres and explained the resistance of thick-walled fibres against buckling by the critical buckling stress, which depends on the response of the fibre to bending stresses in the cell wall.

The stiff cellulose fibrils within the wooden cell wall tend to align in the direction of the load during stretching (Gordon and Jeronimidis 1980, Keckes et al. 2003). The resulting shear stresses force a thin-walled tube to buckle under tensile loading. However, tension buckling seems not to be a problem for artificially produced fibre reinforced thin cylindrical elements because these tubes are usually composed of braided fibres or of fibres which are wound at angles $+\Theta$ and $-\Theta$ to the longitudinal axis resulting in a less anisotropic system (e.g. Harte and Fleck 2000; Soden et al. 1993). In terms of wood tissues tension buckling of the individual fibre within the tissue is impeded by neighbouring cells because of their mostly rectangular shape and the z-helical orientation of the cellulose microfibrils, which results in counterrotating cellulose fibrils of two adjacent cell walls, glued together by the compound middle lamellae, (e.g. Booker 1996; Lichtenegger et al. 1999).

\section{Conclusion}

Tensile tests on single wood fibres were carried out in a microtensile tester operated in an ESEM chamber which allowed straining of single fibres in the hydrated state while observing the deformation behaviour by electron microscopy. Three different fibre types with various cell size and cell wall thickness were observed (earlywood, transition wood and latewood). It could be shown for the mechanically isolated 
fibres that tension buckling appeared as a common failure mechanism in thin-walled cells. With increasing cell wall thickness, tension buckling became less important for crack initiation, whereas structural weak points such as pits or pitfields became more relevant. It can be concluded that cell geometry and cell wall thickness of wood fibres play a major role in stabilizing the "hollow tube" structure in tension and thereby influence the fracture behaviour of the cell. This explains the pronounced differences between the tensile strength of earlywood and latewood fibres (calculation based on cell wall cross-sections).

Acknowledgments We wish to thank the FWF-Fonds zur Förderung der Wissenschaftlichen Forschung, Austria for financial support and John Dunlop for linguistic revision.

Open Access This article is distributed under the terms of the Creative Commons Attribution Noncommercial License which permits any noncommercial use, distribution, and reproduction in any medium, provided the original author(s) and source are credited.

\section{References}

Booker RE (1996) The reasons for the microfibril orientations in the tracheid cell walls of trees. In: Donaldson LA, Singh AP, Butterfield BG, Whitehouse LJ (eds) Recent advances in wood anatomy. New Zealand Forest Research Institute, Rotorua, pp 273-282

Bos HL, Donald AM (1999) In situ ESEM study of the deformation of elementary flax fibres. J Mater Sci 34:3029-3034

Burgert I, Keckes J, Frühmann K, Fratzl P, Tschegg SE (2002) A comparison of two techniques for wood fiber isolation: evaluation by tensile tests of single fibres with different microfibril angle. Plant Biol 4:9-12

Burgert I, Frühmann K, Keckes J, Fratzl P, Stanzl-Tschegg SE (2003) Microtensile testing of wood fibers combined with video extensometry for efficient strain detection. Holzforschung 57:661-664

Burgert I, Frühmann K, Keckes J, Fratzl P, Stanzl-Tschegg S (2005) Properties of chemically and mechanically isolated fibres of spruce (Picea abies [L.] Karst.). Part 2: twisting phenomena. Holzforschung 59:247-251

Danilatos GD (1993) Introduction to the ESEM instrument. Microsc Res Tech 25:354-361

Donald AM (1998) Environmental scanning electron microscopy for the study of wet systems. Curr Opin Colloid In 3:143-147

Donald AM, Baker FS, Smith AC, Waldron KW (2003) Fracture of plant tissues and walls as visualized by environmental scanning electron microscopy. Ann Bot 92:73-77

Eder M, Jungnikl K, Burgert I (2008) A close-up view of wood structure and properties across a growth ring of Norway spruce (Picea abies [L.]. Karst). Trees. doi:10.1007/s00468-008-0256-1

Fletcher AL, Thiel BL, Donald AM (1997) Amplification measurements of alternative imaging gases in environmental SEM. J Phys D Appl Phys 30:2249-2257

Frühmann K, Burgert I, Stanzl-Tschegg S (2003a) Detection of the fracture path under tensile loads through in situ tests in an ESEM chamber. Holzforschung 57:326-332

Frühmann K, Burgert I, Stanzl-Tschegg SE, Tschegg EK (2003b) Mode I fracture behaviour on the growth ring scale and cellular level of spruce (Picea abies [L.] Karst.) and beech (Fagus sylvatica L.) loaded in the TR crack propagation system. Holzforschung 57:653-660

Gordon JE, Jeronimidis G (1980) Composites with high work of fracture. Phil Trans R Soc Lond A-Math Phys Eng Sci 294:545-550

Harte A-M, Fleck NA (2000) On the mechanics of braided composites in tension. Eur J Mech A Solids 19:259-275

Jenkins LM, Donald AM (1997) Use of the environmental scanning electron microscope for the observation of the swelling behaviour of cellulosic fibres. Scanning 19:92-97

Jeronimidis G (1980) The fracture behaviour of wood and the relations between toughness and morphology. Proc R Soc B-Biol Sci 208:447-460 
Keckes J, Burgert I, Frühmann K, Müller M, Kölln K, Hamilton M, Burghammer M, Roth SV, StanzlTschegg S, Fratzl P (2003) Cell-wall recovery after irresversible deformation of wood. Nat Mater 2:810-814

Kifetew G, Sandberg D (2000) Material damage due to electron beam during testing in the environmental scanning electron microscope (ESEM). Wood Fiber Sci 32:44-51

Kitching S, Donald AM (1998) Beam damage of polypropylene in the environmental scanning electron microscope: an FTIR study. J Microsc Oxford 190:357-365

Lichtenegger H, Müller M, Paris O, Riekel C, Fratzl P (1999) Imaging of the helical arrangement of cellulose fibrils in wood by synchrotron X-ray microdiffraction. J Appl Crystallogr 32:1127-1133

Mott L, Shaler S, Groom L, Liang B-H (1995) The tensile testing of individual wood fibers using environmental scanning electron microscopy and video imaging analysis. Tappi 78:143-148

Mott L, Shaler S, Groom LH (1996) A technique to measure strain distributions in single wood pulp fibers. Wood Fiber Sci 28:429-437

Mott L, Groom L, Shaler S (2002) Mechanical properties of individual southern pine fibers. Part II. Comparison of earlywood and latewood fibers with respect to tree height and juvenility. Wood Fiber Sci 34:221-237

Pagano NJ, Halpin JC (1968) Tension buckling of anisotropic cylinders. J Compos Mater 2:154-167

Page DH, El.Hosseiny F, Winkler K (1971) Behaviour of single wood fibres under axial tensile strain. Nature 229:252-253

Page DH, El-Hosseiny F (1983) The mechanical properties of single wood pulp fibres. Part VI. Fibril angle and the shape of the stress-strain curve. J Pulp Pap Sci 9:1-2

Royall CP, Thiel BL, Donald AM (2001) Radiation damage of water in environmental scanning electron microscopy. J Microsc Oxford 204:185-195

Sippola M, Frühmann K (2002) In situ longitudinal tensile tests of pine wood in an environmental scanning electron microscope. Holzforschung 56:669-675

Soden PD, Kitching R, Tse PC, Tsavalas Y (1993) Influence of winding angle on the strength and deformation of filament-wound composite tubes subjected to uniaxial and biaxial loads. Compos Sci Technol 46:363-378

Stokes DJ (2003) Recent advances in electron imaging, image interpretation and applications: environmental scanning electron microscopy. Philos Trans R Soc A-Math Phys Eng Sci 361:2771-2787 